the efficacy of new antivenoms and in determining their effective dosage.

We thank Dr. N. Veall for his help with the radioimmunoassay. This study was supported by grants from the United Kingdom Medical Research Council and from the Wellcome Trust.

\section{References}

Coulter, A. R., Sutherland, S. K., and Broad, A. J. (1974). Fournal of Immunological Methods, 4, 297.

Greenwood, B. M., and Whittle, H. C. (1974). Clinical and Experimental Immunology, 16, 413. Muelling, R. J., Samson, R. F., and Beven, T. (1957). American fournal of
Clinical Pathology, 28, 489.

Trethewie, E. R., and Thomas, W. L. (1969). Toxicon, 7, 243.

\title{
Effect of Age and Menopausal Status on Estimates of Oestrogen Binding by Human Malignant Breast Tumours
}

\author{
H. BRAUNSBERG, V. H. T. JAMES, C. W. JAMIESON, S. DESAI, \\ A. E. CARTER, M. HULBERT
}

British Medical fournal, 1974, 4, 745-747

\section{Summary}

The uptake of oestradiol by human breast-tumour tissue estimated by in-vivo and in-vitro techniques has been examined in relation to patients' ages and menopausal status. Results from in-vivo studies showed no convincing correlations, while in-vitro results were significantly correlated with menopausal status. There was a significant correlation between results obtained by the two techniques.

\section{Introduction}

After claims that the presence of oestrogen-binding components ("receptors") in human malignant breast tumours may be related to their response to endocrine therapy (Jensen et al., 1973; Maass et al., 1972) much work has recently been published on the quantitative determination of these substances. Though estimates of tumour affinity for oestrogen by an in-vivo tracer infusion technique (Braunsberg et al., 1967) may yield results which are independent of plasma oestrogen levels in-vitro methods involving incubation of tracer with tissue extracts (Korenman and Dukes, 1970) are believed to estimate free-that is, unoccupied-oestrogen binding sites because the endogenous hormone dissociates only slowly from its complex (Feherty et al., 1971). It is therefore possible that the estimated concentrations of "receptor" and the incidence of "receptorpositive" tumours depend on plasma oestrogen levels and thus on the patient's age and menopausal status.

Some studies support this possibility (Maass et al., 1972; Feherty et al., 1971; Savlov et al., 1974; Spaeren et al., 1973). We report here a statistical analysis of results for 105 tumours

\footnotetext{
Department of Chemical Pathology, St. Mary's Hospital Medical School, London W2 1PG

H. BRAUNSBERG, PH.D., M.R.C.PATH., Lecturer

V. H. T. JAMES, D.SC., M.R.C.PATH., Professor
}

Surgical Unit, St. Mary's Hospital Medical School, London W2 1PG C. W. JAMIESON, M.s., F.R.C.S., Consultant Surgeon (Present address: St. Thomas's Hospital, London S.E.1)

S. DESAI, F.R.C.S., Lecturer

King Edward Memorial Hospital, Ealing, London W.13

A. E. CARTER, F.R.C.S., Consultant Surgeon

Department of Radiotherapy, St. Mary's Hospital, London, W.2

M. HULBERT, D.M.R.E., F.F.R., Consultant Radiotherapist studied in-vivo (Braunsberg et al., 1967) and 76 tumours studied by an in-vitro technique (Feherty et al., 1971).

\section{Patients and Methods}

Patients were grouped according to their age or their menopausal status; group 1 were premenopausal, group 2 were symptomatically menopausal, group 3 had been postmenopausal for a period up to and including five years, and group 4 had been postmenopausal for more than five years. All tumours were primary lesions whose malignancy was confirmed histologically.

In the in-vivo study the 105 patients were infused with tritium-labelled oestradiol at a constant rate for at least three hours before and during surgery. Under these conditions equilibrium is approached in the tissues between isotopic oestrogen and the endogenous exchangeable hormone. Tissue and plasma obtained at operation were extracted (Braunsberg et al., 1967) to yield the free steroid moiety, and the concentration of radioactive steroid in the tissue was a measure of the concentration of endogenous hormone present (Braunsberg and James, 1967). Oestrogen uptake was expressed as the ratio of radioactivity per gram of tissue $(T)$ to that per millilitre of plasma (P).

For the in-vitro study the method of Feherty et al., (1971) was used. Tissue extracts were incubated with varying amounts of tritium-labelled oestradiol which attaches to binding sites if present. Subsequent incubation with dextran-coated charcoal removed free oestradiol and dissociated the steroid from lowaffinity sites leaving that bound to high-affinity "receptor" in solution. Determination of bound radioactivity at different concentrations of tracer yielded estimates of binding sites.

\section{Results}

For both the in-vivo and the in-vitro studies the logarithms of the values estimated gave approximately Gaussian frequency distributions. All Student's $t$ tests were therefore applied to logarithmic data.

The results for $T: P$ (in-vivo technique) according to patients' ages are shown in fig 1 . There was no significant difference between the age groups. The data plotted according to menopausal status are shown in fig. 2. No significant differences were found between the groups, but when groups 1,2 , and 3 were combined the mean $\mathrm{T}: \mathrm{P}(2.1)$ was just significantly different from that (3.2) for group $4(P<0.05)$.

In the in-vitro study 58 out of 76 tumours $(76 \%)$ were found to bind oestradiol-that is, to be "positive." The incidence of 


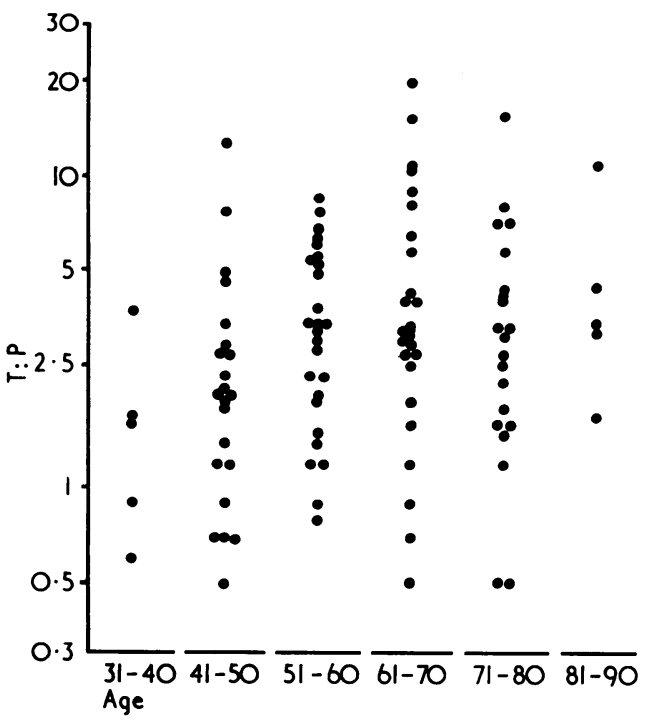

FIG. 1-Tissue : plasma ratio of free steroid radioactivity $(T: P)$ after infusion of tritium-labelled oestradiol in relation to patients' ages.

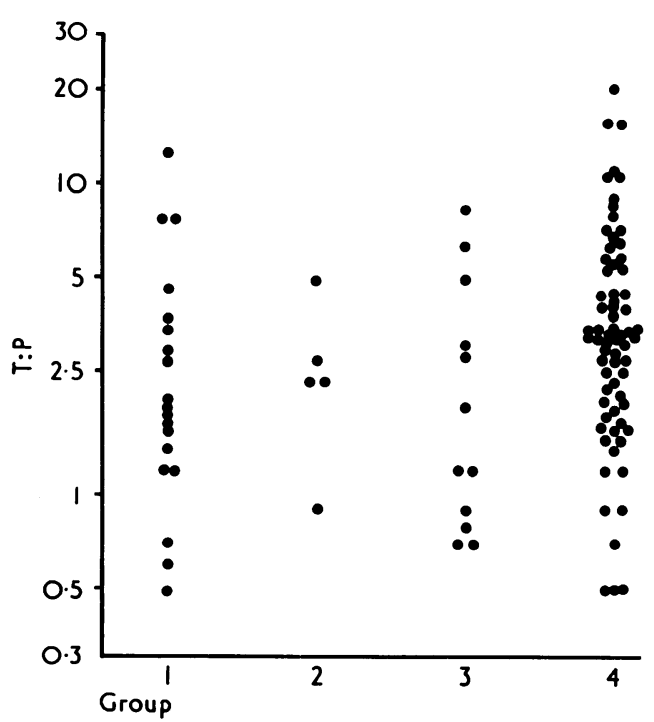

FIG. 2-Tissue : Plasma ratio of free steroid radioactivity $(T: P)$ in relation to menopausal status.

"positive" tumours in relation to age is shown in table I. The younger patients showed a high incidence while those in the fifth and sixth decades showed lower incidences. Greater proportions of "positive" tumours were again found at higher ages. These data are shown in relation to menopausal status

TABLE I-Incidence of Receptor-positive Tumours (In-vitro Assay) in Relation to Patients' Ages

\begin{tabular}{lc|c|c|c|c|c|c}
\hline Age group (years): & $31-40$ & $41-50$ & $51-60$ & $61-70$ & $71-80$ & $81-90$ \\
\hline $\begin{array}{l}\text { No. of patients } \\
\begin{array}{l}\text { No. (\%) with "positive"; } \\
\text { tumours }\end{array}\end{array}$ & $2(100)$ & $17(94)$ & $13(68)$ & $13(65)$ & 10 (77) & 3 (75) \\
\hline
\end{tabular}

TABLE II-Incidence of Receptor positive Tumours (In-vitro Assay) in Relation to Patients' Menopausal Status

\begin{tabular}{|c|c|c|c|c|c|}
\hline Group & .. & 1 & 2 & 3 & 4 \\
\hline $\begin{array}{l}\text { No. of patients } \\
\text { No. }(\%) \text { with positiv }\end{array}$ & cumours... & $12 \frac{13}{(92)}$ & $5\left(\begin{array}{l}5 \\
(100)\end{array}\right.$ & $4 \stackrel{5}{(80)}$ & $\begin{array}{c}53 \\
37(70)\end{array}$ \\
\hline
\end{tabular}

in table II. The incidence of "positive" tumours was higher in groups 1 to 3 than in group 4.

Estimates of binding-site concentrations ( $\mathrm{fmol} / \mathrm{mg}$ wet weight) for "positive" tumours are plotted against patients' ages in fig. 3. There seemed to be a trend towards higher results

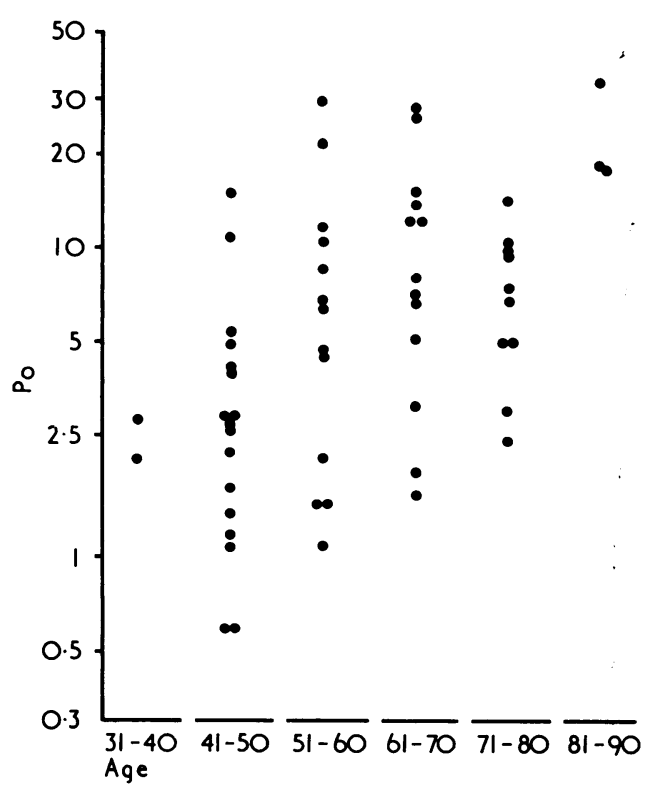

FIG. 3-Estimates of concentrations of binding sites $\left(P_{0}\right)$ for "positive" tumours in relation to age.

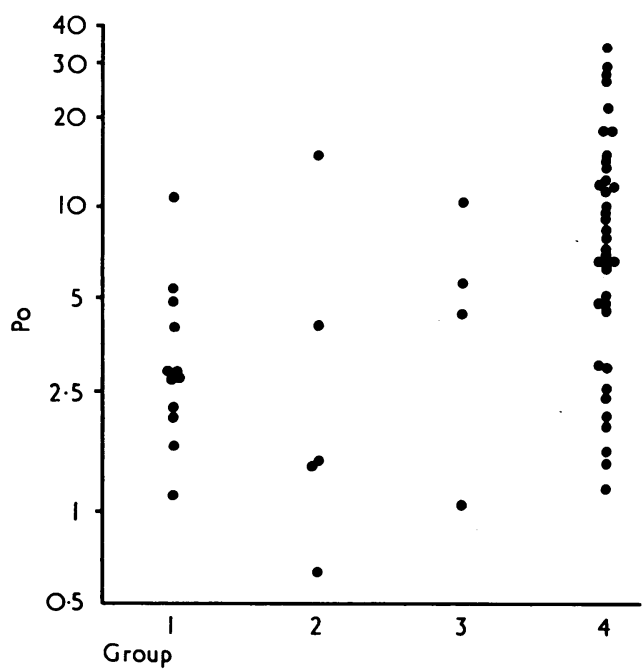

FIG. 4-Estimates of concentrations of binding sites $\left(P_{0}\right)$ in relation to menopausal status.

in the older patients. The data were plotted in relation to menopausal status in fig. 4. There were few results in groups 1,2 , and 3 , but when the mean for groups 1,2 , and 3 was compared to that for group 4 the difference was highly significant $(\mathrm{P}<0.001)$.

The results of a study in which 23 tumours were examined by both the in-vivo and the in-vitro techniques are shown in fig. 5. The small amount of tritium present in the tissues as a result of the infusions was negligible in relation to the concentrations added in the in-vitro assay. Though there was a significant correlation $(r=0.81 ; P<0.001)$ the figures were widely scattered at all levels. 


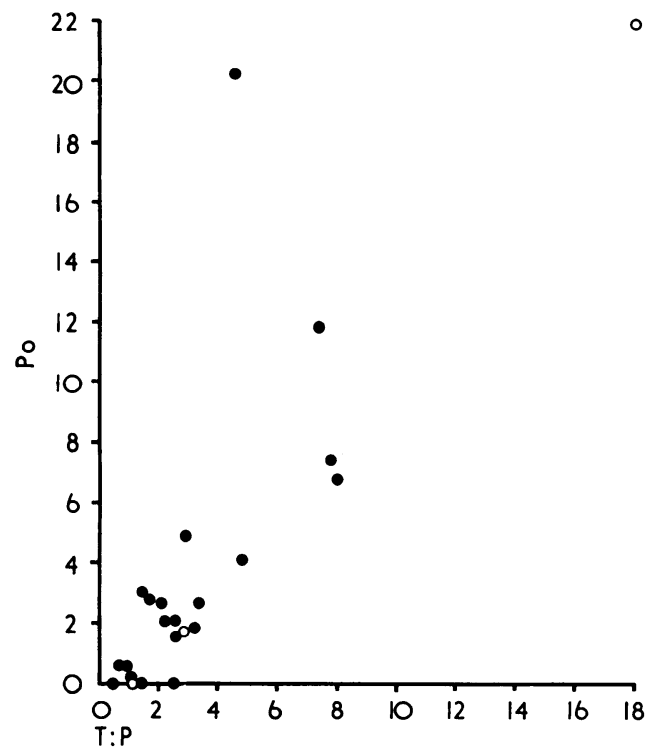

FIG. 5-Relation between in-vivo $(T: P)$ and in vitro $\left(P_{0}\right)$ estimates of oestradiol binding by malignant breast tumours. $=$ Primary lesions. $\mathrm{O}=$ Metastatic tumours.

\section{Discussion}

While in-vitro estimates of concentrations of oestrogen-binding components in breast-tumour tissues seem to be related to a patients' age and menopausal status no convincing correlation could be shown for results of uptake studies in vivo. A possible explanation is that in-vivo, where equilibrium is approached between the tracer and endogenous hormone in blood and tissue, results are independent of the plasma level of endogenous oestrogen, while in-vitro much of the endogenous hormone remains attached to binding sites and the proportion of unoccupied sites present is related to plasma oestrogen concentration. In addition, it is likely that in the in-vivo studies some tracer steroid binds to low-affinity binding components, now known to be present in tumour tissue (Jensen et al., 1973), while such binding is largely dissociated in the in-vitro method (Feherty et al., 1971). For tumours with a high capacity of lowaffinity components estimates of high-affinity "receptors" are unreliable by both techniques. Furthermore, the in-vivo method probably yields results which are less precise than those by the in-vitro technique. In spite of these differences a correlation has been found between the in-vivo and in-vitro results and it is likely that when "receptor" concentrations are high both methods are capable of indicating this clearly. At lower "receptor" concentrations, however, results by the in-vitro method may become more dependent on endogenous levels of oestrogen.

Other work has indicated a relationship between results of in-vitro analyses and patients' ages and menopausal status. Of the series reported by Savlov et al. (1974) the highest values were found in women over the age of 55. Spaeren et al. (1973) found considerably lower concentrations of binding sites in women aged 30-49 than in the older patients. We have provided statistical evidence of a highly significant relationship of these data to menopausal status.

Our results are to some extent, however, at variance with those of others. Oestrogen binding sites were detected in 21 out of 23 women in groups 1,2, and 3 and in 37 out of 53 women in group 4. In contrast, Feherty et al. (1971), Savlov et al. (1974), and Spaeren et al. (1973) reported a lower incidence of "positive" tumours in younger or premenopausal women than in older patients. This discrepancy is difficult to explain, particularly as the overall incidences of "positive" tumours in two of the three studies (70\% of 53, Feherty et al. (1971); $73 \%$ of 251, Spaeren et al. (1973)) are not very different from that found in the present work ( $76 \%$ of 76 ).

It has been reported (Jensen et al., 1973; Maass et al., 1972) that there is much prognostic significance in the presence of oestrogen receptors in breast-tumour tissue and that there is little likelihood of a patient responding to endocrine therapy if oestrogen receptors cannot be detected. Our own data from an in-vivo study (Braunsberg et al., 1973) and from our in-vitro determinations suggest that though this conclusion is true in most cases there are occasional exceptions for which no obvious explanation exists. Similar findings have also been reported at a recent meeting (McGuire et al., in press) by several other groups using in-vitro methods. It would therefore seem that a patients' response to treatment cannot yet be predicted with complete confidence from these biochemical studies. Though this may be a consequence of technical problems in the estimation of receptors other factors-such as menopausal status and stage of the disease-may play an important part in some patients.

We thank the surgeons of St. Mary's Hospital for the opportunity to study patients under their care and for their generous co-operation and Mrs. Doreen Irving for advice and help with statistical evaluation. This work was supported by the Cancer Research Campaign.

\section{References}

Braunsberg, H., Irvine, W. T., and James, V. H. T. (1967). British fournal of Cancer, 21,714 .

Braunsberg, H., and James, V. H. T. (1967). Fourinal of Clinical Endocrinology and Metabolism, 27, 1174 .

Braunsberg, H., et al., (1973). Lancet, 1, 163.

Feherty, P., Farrer-Brown, G., and Kellie, A. E. (1971). British fournal of Cancer, 25, 697

Jensen, E. V., et al. (1973). In Recent Results in Cancer Research, vol. 42, ed. M. L. Griem et al., p. 55 . Heidelberg, Springer-Verlag.

Korenman, S. G., and Dukes, B. A. (1970). ₹ournal of Clinical Endocrinology and Metabolism, 30,639.

Maass, H., et al. (1972). American fournal of Obstetrics and Gynecology, 113, 377.

McGuire, W. L., Carbone, P. P., and Vollmer, E. P. (editors). (In press). Estrogen Receptor in Human Breast Cancer. New York, Raven Press.

Savlov, E. D., et al. (1974). Cancer, 33, 303.

Spaeren, U., et al. (1973). European fournal of Cancer, 9, 353. 